Historic, archived document

Do not assume content reflects current scientific knowledge, policies, or practices. 
United States Department of Agriculture

Forest Service

Intermountain

Research Station

Research Paper INT-367

June 1986

选的
Mountain Pine Beetle in Ponderosa Pine: Effects of Phloem Thickness and Egg Gallery Density

Gene D. Amman Judith E. Pasek

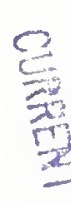

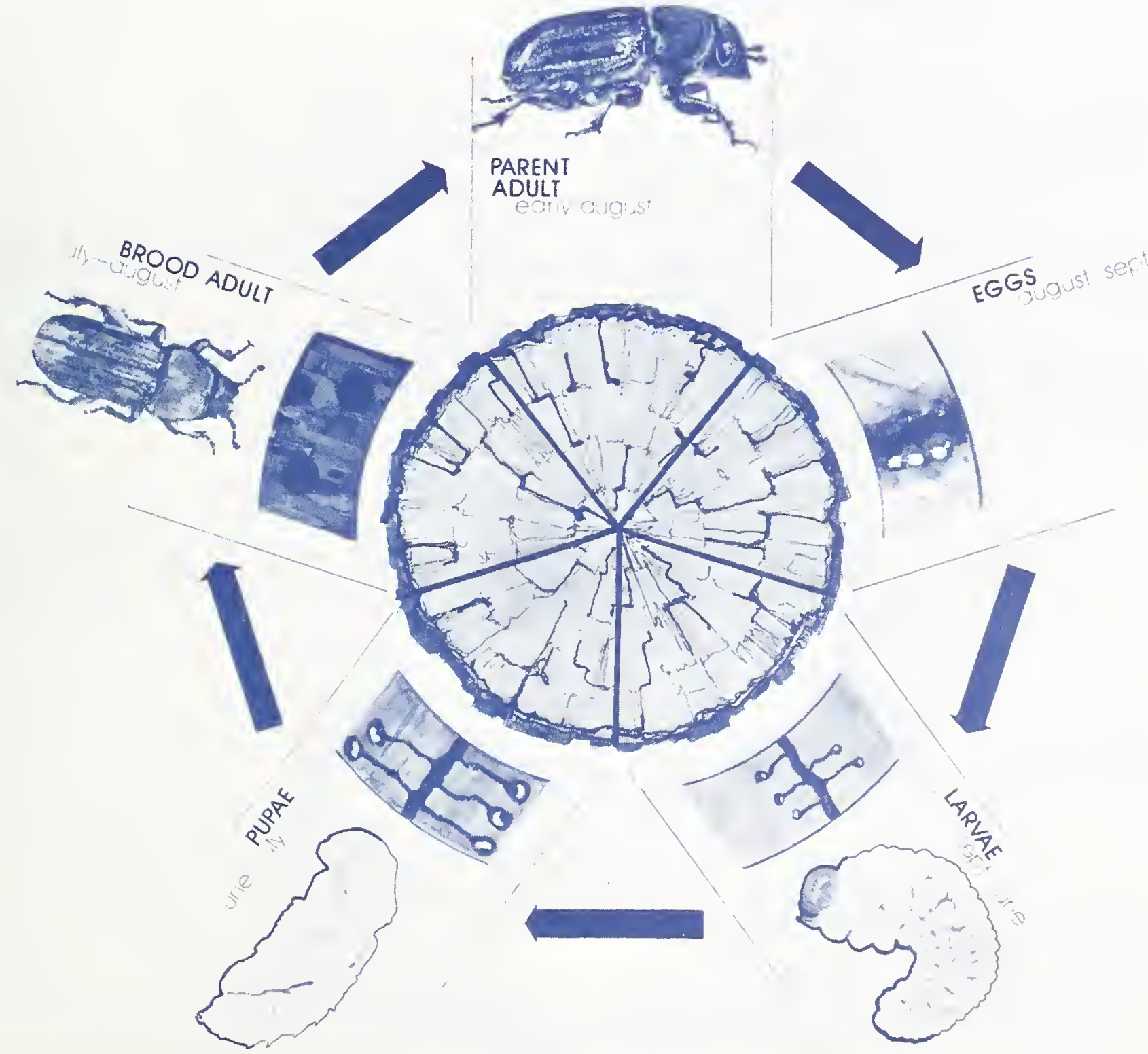

$x$

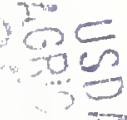

क 


\section{THE AUTHORS}

GENE D. AMMAN is project leader of the Mountain Pine Beetle Population Dynamics research work unit in Ogden, UT. He joined the work unit in 1966. Prior to joining the Intermountain Station, he was research entomologist with the Southeastern Forest Experiment Station in Asheville, NC, doing biological control and ecological research on the balsam woolly aphid. He began his career with the Rocky Mountain Forest and Range Experiment Station in Fort Collins, $\mathrm{CO}$, as research assistant on sampling populations and mortality factors of mountain pine beetle and spruce bark beetle. He has B.S. and M.S. degrees from Colorado State University and a Ph.D. degree from the University of Michigan.

JUDITH E. PASEK is research entomologist with the Rocky Mountain Forest and Range Experiment Station's Protection and Improvement of Trees in the Great Plains research work unit in Lincoln, NE. At the time of this study, she was biological technician on the Mountain Pine Beetle Population Dynamics research work unit in Ogden. She holds a B.S. degree from the University of Michigan, an M.S. degree from the University of Missouri, and presently is a Ph.D. degree candidate at the University of Nebraska.

\section{ACKNOWLEDGMENTS}

We acknowledge the helpful reviews of an earlier draft of this manuscript by Drs. A. A. Berryman, Washington State University, Pullman; J. L. Foltz, University of Florida, Gainesville; R. A. Haack, Michigan State University, East Lansing; M. W. Stock, University of Idaho, Moscow; and R. N. Coulson and T. L. Wagner, Texas A. \& M. University, College Station. We also gratefully acknowledge assistance from C. E. Jensen (now retired), Intermountain Research Station, Ogden, in developing the threedimensional relationships in the data, describing them algebraically, and reviewing the manuscript.

\section{RESEARCH SUMMARY}

Some effects of ponderosa pine (Pinus ponderosa Dougl. ex Laws.) phloem thickness on mountain pine beetle (Dendroctonus ponderosae Hopkins [Coleoptera: Scolytidae]) were studied in relation to beetle attack and gallery densities. Brood production was positively related to phloem thickness, beetle attack density, and egg gallery density, but showed an asymptotic relationship at high attack and gallery densities. Female length was positively related to phloem thickness but negatively related to increasing egg gallery density. Significantly greater proportions of females emerged from medium and thick phloem than from thin phloem, but sex ratio was not related to attack density. The time of emergence was delayed in thin phloem compared to medium and thick phloem.

June 1986

Intermountain Research Station

324 25th Street

Ogden, UT 84401 


\title{
Mountain Pine Beetle in Ponderosa Pine: Effects of Phloem Thickness and Egg Gallery Density
}

\author{
Gene D. Amman \\ Judith E. Pasek
}

\section{INTRODUCTION}

The mountain pine beetle (MPB) (Dendroctonus ponderosae Hopkins [Coleoptera: Scolytidae]) kills more pine trees in the Western United States than any other insect. During epidemics, the beetle frequently kills over a million trees a year in a single National Forest (Klein and others 1979) or National Park (McGregor and others 1978).

Hopkins (1909) observed during an outbreak that as a rule the largest and best trees are attacked firstlodgepole (Pinus contorta Dougl.) and ponderosa (P. ponderosa Dougl. ex Laws.) pines. He further states that "it is only in the thicker bark on the lower portion of the trunk of the medium to larger trees [lodgepole pine] that beetle broods will reach their best development." Craighead and others (1931) state: "In contrast to the trees [lodgepole pine] selected under endemic conditions, it is the larger thick-barked trees that are first attacked during epidemics." The reason for this has been related to thick phloem, the food of beetle larvae, in such trees (Amman 1969). Beetle production, measured as beetle emergence holes, in lodgepole was directly related to crevice thickness of bark on the dead trees. Amman (1969) also showed phloem thickness on living lodgepole pine was highly correlated with bark crevice thickness and suggested that beetle production is dependent on phloem thickness of the infested tree. Subsequently, in a laboratory study, positive correlations between beetle production and phloem thickness were demonstrated (Amman 1972a; Amman and Pace 1976). Phloem thickness of the host tree may also be important in dynamics of other bark beetles. Haack and others (1984) found significant correlations between egg gallery construction and oviposition of Ips calligraphus (Germar) and thickness of slash pine ( $P$. elliottii Engelm.) phloem.

Because of the significant role phloem thickness plays in the dynamics of MPB in lodgepole pine forests, similar studies were initiated in ponderosa pine, another important host of the beetle and one in which losses continue to be high (McGregor 1985). Blackman (1931) related MPB brood production in ponderosa pine to crown characteristics and rainfall. Under conditions of normal rainfall, trees having heavy crowns produced 42 percent more beetles than trees of medium crowns, and 92 percent more beetles than trees of light crowns. This relationship to crown characteristics during normal rainfall suggests that phloem thickness may be involved because trees having large crowns are probably the most vigorous and would have the thickest phloem. Cole (1973) found lodgepole phloem thickness to be significantly and positively correlated with characteristics of good tree vigor. Therefore, a study of MPB brood production in ponderosa pine of different phloem thickness was conducted. The objectives of the study were (1) to determine beetle brood production in relationship to phloem thickness, beetle attack density, and egg gallery density, and (2) to determine effects of phloem thickness and attack and gallery densities on beetle size, sex ratio, and rate of emergence.

\section{MATERIALS AND METHODS}

Three uninfested ponderosa pine trees (one with thin phloem, one with medium, and one with thick) were felled on the Ashley National Forest in northeastern Utah in November 1979. In addition, three infested trees were felled at the same place and time. Billets $50 \mathrm{~cm}$ long were cut from each tree and taken to our laboratory in Ogden, UT, where the ends of the billets were waxed to slow moisture loss. Uninfested billets were stored at $2{ }^{\circ} \mathrm{C}$. Infested billets were kept at room temperatures of 20 to $27{ }^{\circ} \mathrm{C}$ so immature beetles could complete development and emerge.

In January 1980 , we delineated 25 areas $(15.2 \mathrm{~cm}$ wide by $30.5 \mathrm{~cm}$ tall) on uninfested billets taken from each of the three trees. Phloem thickness measurements were made in the center of the four sides of each of the 25 areas from each tree. Mean phloem thickness for each tree was thin $(\overline{\mathrm{x}}=1.53 \mathrm{~mm}$; sd $=0.23)$, medium $(\overline{\mathrm{x}}=$ $2.88 \mathrm{~mm}$; sd $=0.43)$, and thick $(\overline{\mathrm{x}}=3.49 \mathrm{~mm}$; $\mathrm{sd}=$ $0.44)$. A $2.5-\mathrm{cm}$-wide strip of bark was removed from the perimeter of each area to confine developing larvae. Exposed sapwood and bark edges were waxed to slow moisture loss.

To provide a start for egg galleries, vertical holes ( $5 \mathrm{~mm}$ in diameter and $2.5 \mathrm{~cm}$ long) were drilled with the long axis of the billet in the bark along the lower edge of each area, and one pair of beetles was introduced into each hole. Sex of beetles was determined by characteristics of the seventh abdominal tergum (Lyon 1958). Holes and beetle introductions were evenly spaced and varied 
from one to five per area, depending upon desired attack density. Each attack density was replicated five times in each phloem thickness, resulting in 75 areas.

The newly infested billets were kept upright at room temperatures of 20 to $27^{\circ} \mathrm{C}$ and humidity of 20 to 40 percent throughout the experiment, which lasted about 4 months. Plastic screen cages were placed over the infested areas and stapled to the sapwood. A plastic test tube attached to the base of each cage served to catch emerging beetles. Beetles were collected, counted, and sexed daily. Length of each beetle was measured with an ocular micrometer in a dissecting microscope. After emergence was completed, bark was peeled from each of the 75 areas. Bark areas were measured and the area at the base where entrance holes were made was deleted. In addition, area of phloem injured when the tree was felled and thus avoided by beetles was subtracted from bark area. Therefore, the area available to the beetles was less than the approximately $465 \mathrm{~cm}^{2}$ of each delineated bark area. Remaining beetles, length of egg gallery, and successful attacks (egg gallery starts) were counted.

Because egg gallery was not constructed in four areas, analyses were based on the remaining 71 areas. Also, some beetles did not make egg gallery; therefore, numbers of observations in each attack density differed from the five planned in each phloem thickness. To determine if excessive drying of bark and wood occurred during beetle rearing, thus possibly affecting beetle survival, an increment core about 1 inch long was taken from the center of each area with an increment hammer and placed in a glass vial. Moisture content of the wood then

Table 1-Data from study of mountain pine beetle production in ponderosa pine phloem of different

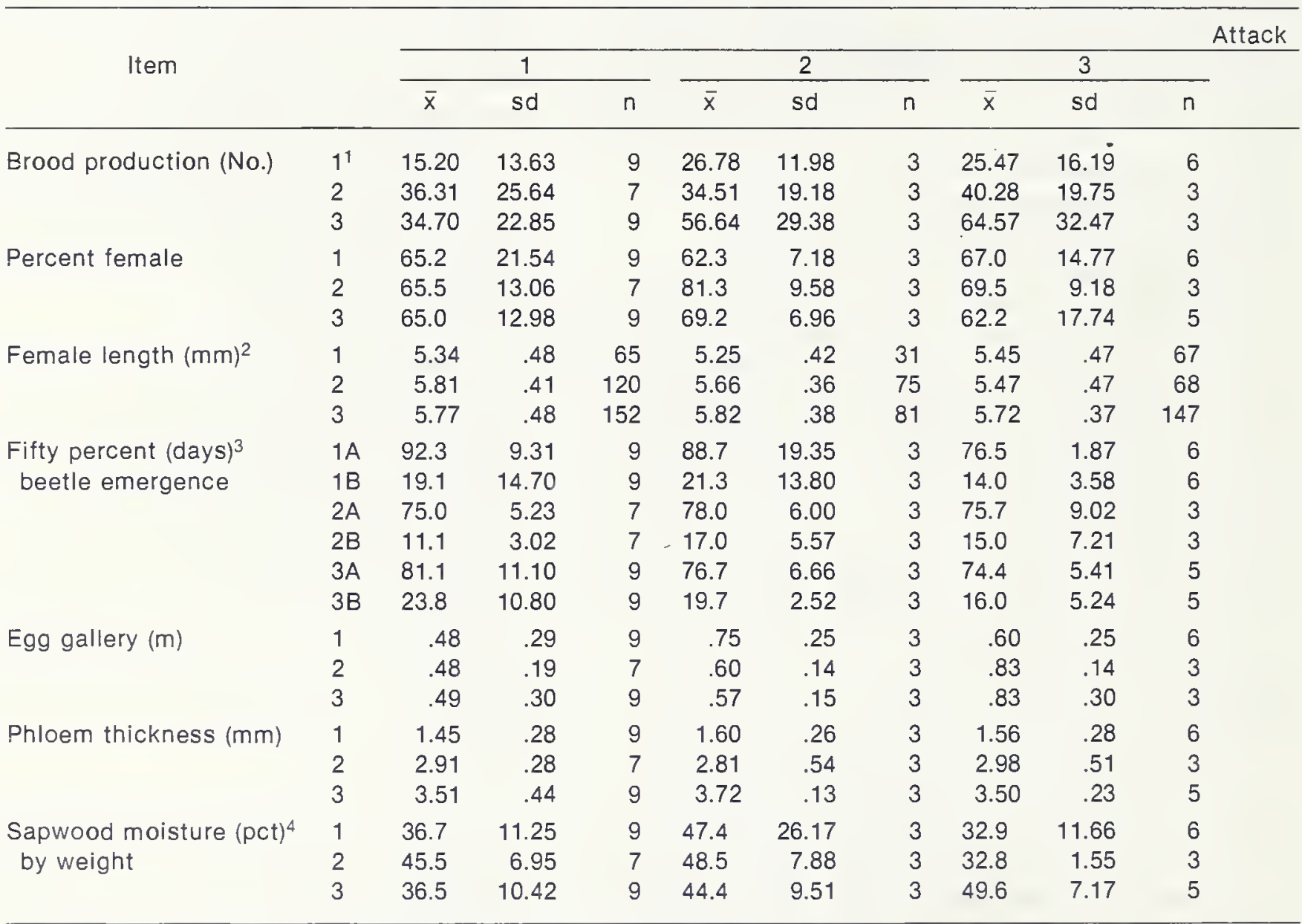

11,2 , and 3 represent thin, medium, and thick phloem, respectively.

${ }^{2}$ Female length is measured from front of the head to tip of the elytra.

${ }^{3} \mathrm{~A}$ is the number of days for 50 percent of the new adults to emerge, starting from the day parent beetles were introduced into a bark area to oviposit. $B$ is the number of days for 50 percent of the new adults to emerge, starting from the day the first new adult emerged from a bark area.

${ }^{4}$ Sapwood moisture was determined after beetle emergence was completed. 
was determined by weighing, drying in an oven, and reweighing the cores.

\section{ANALYSIS OF DATA}

The original data were expanded to represent beetles, successful attacks, and egg gallery per $930 \mathrm{~cm}^{2}$ for ease of comparison with other studies using this size area. Using these data, brood production (BP) was initially subjected to multiple regression screens in two forms, first as a function of phloem thickness (PT) and gallery density (GD), and second using PT and attack density (AD) to determine if effects of GD and AD were similar. Multiple regression screens also were used to test for effects of GD, AD, and PT on beetle size. Graphic and descriptor development procedures follow those specified in Matchacurves 1, 2, and 3 (Jensen 1973; Jensen and
Homeyer 1970, 1971). Each three-dimensional model was developed graphically, using trends in the data to arrive at smoothed curve forms. These were fitted through the data by approximate "least deviations." The resulting graphic forms were described algebraically. These descriptors were given a least squares adjustment $(<5$ percent in all cases) to their respective data sets.

ANOVA was used to test for differences in percentages (arc sine transform) of new adults that were female, and the Hartley Multiple Range Test was used to test for differences between means (Snedecor 1956).

\section{RESULTS AND DISCUSSION}

We concentrated on four results from this study: brood production, MPB size, sex ratio, and emergence time (table 1).

thickness at different beetle attack densities $/ 930 \mathrm{~cm}^{2}$

\begin{tabular}{|c|c|c|c|c|c|c|c|c|c|c|c|}
\hline \multicolumn{3}{|c|}{4} & \multicolumn{3}{|c|}{5} & \multicolumn{3}{|c|}{6} & \multicolumn{3}{|c|}{7} \\
\hline $\bar{x}$ & sd & $n$ & $\bar{x}$ & $\mathrm{sd}$ & $n$ & $\bar{x}$ & $\mathrm{sd}$ & $n$ & $\bar{x}$ & sd & $n$ \\
\hline 6.31 & - & 1 & 21.21 & 8.21 & 2 & 30.51 & - & 1 & 31.10 & 15.53 & 2 \\
\hline 60.43 & 20.70 & 7 & 39.07 & - & 1 & 70.91 & 41.62 & 2 & - & - & - \\
\hline 61.88 & 17.23 & 3 & 78.53 & 18.80 & 3 & 41.48 & - & 1 & - & - & - \\
\hline 20.0 & - & 1 & 72.6 & 23.05 & 2 & 70.0 & - & 1 & 80.7 & 13.15 & 2 \\
\hline 69.6 & 13.12 & 7 & 53.8 & - & 1 & 53.6 & 10.04 & 2 & - & - & - \\
\hline 68.6 & 3.35 & 3 & 68.0 & 3.14 & 3 & 73.8 & - & 1 & - & - & - \\
\hline 5.40 & - & 1 & 5.27 & .44 & 17 & 5.18 & .72 & 14 & 5.16 & .43 & 36 \\
\hline 5.47 & .42 & 225 & 5.21 & .46 & 15 & 5.34 & .52 & 50 & - & - & - \\
\hline 5.56 & .34 & 93 & 5.59 & .66 & 110 & 5.41 & .33 & 30 & - & - & - \\
\hline 104.0 & - & 1 & 85.5 & 17.68 & 2 & 80.0 & - & 1 & 82.5 & 7.78 & 2 \\
\hline 36.0 & - & 1 & 15.0 & 8.49 & 2 & 21.0 & - & 1 & 20.5 & .71 & 2 \\
\hline 72.6 & 3.99 & 7 & 82.0 & - & 1 & 76.0 & 1.41 & 2 & - & - & - \\
\hline 11.0 & 1.83 & 7 & 17.0 & - & 1 & 13.0 & 4.24 & 2 & - & - & - \\
\hline 76.7 & 3.51 & 3 & 69.3 & 2.89 & 3 & 73.0 & - & 1 & - & - & - \\
\hline 20.7 & 3.51 & 3 & 12.0 & 4.36 & 3 & 17.0 & - & 1 & - & - & - \\
\hline 1.12 & - & 1 & 1.43 & .09 & 2 & 1.03 & - & 1 & 1.69 & .19 & 2 \\
\hline 1.27 & .24 & 7 & 1.36 & - & 1 & 2.10 & .06 & 2 & - & - & - \\
\hline 1.37 & .05 & 3 & 1.45 & .40 & 3 & 2.11 & - & 1 & - & - & - \\
\hline 1.47 & - & 1 & 1.44 & .31 & 2 & 1.78 & - & 1 & 1.70 & .18 & 2 \\
\hline 2.87 & .31 & 7 & 2.49 & .31 & 1 & 3.09 & .59 & 2 & - & - & - \\
\hline 3.37 & .12 & 3 & 3.50 & .49 & 3 & 3.18 & - & 1 & - & - & - \\
\hline 31.4 & - & 1 & 41.6 & 20.93 & 2 & 26.0 & - & 1 & 33.2 & 8.06 & 2 \\
\hline 39.3 & 10.92 & 7 & 22.1 & - & 1 & 28.3 & 21.21 & 2 & - & - & - \\
\hline 42.3 & 9.22 & 3 & 28.9 & 4.09 & 3 & 50.1 & - & 1 & - & - & - \\
\hline
\end{tabular}




\section{Brood Production}

A multiple regression screen of brood production as a function of phloem thickness and gallery density showed gallery density (GD) accounted for a larger amount of variance ( 30 percent) in brood production than did phloem thickness (PT) (20 percent) (table 2). In a second screen, substituting attack density (AD) for GD, PT accounted for a larger amount of variance (20 percent) than AD (13 percent) (table 2). The PT effect in each case was clearly linear, while both GD and AD were quadratic in nature. Each regression was highly significant $(\mathrm{P}<0.005)$. With this information as a base, data were partitioned in each case to examine more closely the nature of the generally quadratic effects of GD and AD. The results are shown in figures 1 and 2 . Brood production was significantly and positively related to egg gallery density and phloem thickness $\left(R^{2}=0.55\right.$; $\mathrm{P}<0.01$ ). For example, at $0.3 \mathrm{~m}$ of egg gallery per $930 \mathrm{~cm}^{2}$, average brood production was 10 for thin phloem, 23 for medium, and 33 for thick (fig. 1). At $2.1 \mathrm{~m}$ of egg gallery per $930 \mathrm{~cm}^{2}$ of bark, brood production was 27 for thin, 56 for medium, and 75 for thick. Brood production reached an asymptote at about $1.5 \mathrm{~m}$ of egg gallery per $930 \mathrm{~cm}^{2}$ with no drop in brood production out to $2.1 \mathrm{~m}$ of gallery per $930 \mathrm{~cm}^{2}$ of bark, the highest egg gallery density observed in the test.

Brood production was significantly related to PT and $\mathrm{AD}$, the combined effect being similar to that of PT and GD $\left(R^{2}=0.38 ; P<0.01\right)$. Brood production for seven attacks per $930 \mathrm{~cm}^{2}$ was 24 in thin phloem, 45 in medium, and 70 in thick. Curves flattened considerably

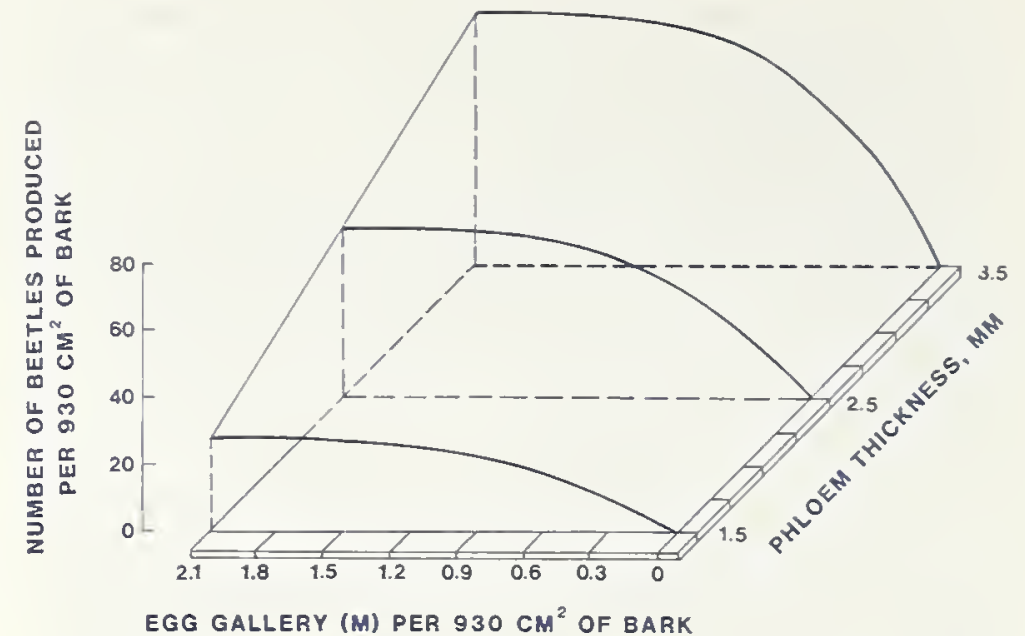

Figure $1-$ Mountain pine beetle brood production per unit area of ponderosa pine bark increases with both egg gal. lery density and phloem thickness.

$\mathrm{BP} / 930 \mathrm{~cm}^{2}=0.9544\left[\mathrm{UI}-\frac{\mathrm{UI}}{7^{n}}(7-3.281 \mathrm{GD})^{n}\right]$

$\mathrm{UI}=(836.766)(0.03937 \mathrm{PT})^{1.2}$

$=$ upper intercept

$n=2.92+83.87(0.03937 P T)^{2.3}$

where

PT $=$ phloem thickness in millimeters

$G D=$ egg gallery density in meters per $930 \mathrm{~cm}^{2}$

$P<0.01$

$R^{2}=0.55$

Limits: $0 \leq \mathrm{GD} \leq 2.1$.

Table 2-Multiple regression screen of mountain pine beetle brood production as a function of ponderosa pine phloem thickness (PT) and egg gallery density (GD), and ponderosa pine phloem thickness (PT) and attack density (AD)

\begin{tabular}{|c|c|c|c|}
\hline \multicolumn{2}{|c|}{ Phloem thickness - gallery density } & \multicolumn{2}{|c|}{ Phloem thickness - attack density } \\
\hline Variables & $R^{2}$ & Variables & $R^{2}$ \\
\hline GD & 0.30 & $A D$ & 0.13 \\
\hline $\mathrm{GD}^{2}$ & .23 & $A D^{2}$ & .08 \\
\hline PT & .20 & PT & .20 \\
\hline $\mathrm{PT}^{2}$ & .18 & $\mathrm{PT}^{2}$ & .18 \\
\hline$G D \times G D^{2}$ & .35 & $A D \times A D^{2}$ & .20 \\
\hline $\mathrm{GD} \times \mathrm{PT}$ & .49 & $A D \times P T$ & .35 \\
\hline $\mathrm{GD} \times \mathrm{PT}^{2}$ & .47 & $A D \times P T^{2}$ & .33 \\
\hline $\mathrm{GD}^{2} \times \mathrm{PT}$ & .40 & $A D^{2} \times P T$ & .30 \\
\hline $\mathrm{GD}^{2} \times \mathrm{PT}^{2}$ & .38 & $A D^{2} \times P T^{2}$ & .28 \\
\hline $\mathrm{PT} \times \mathrm{PT}^{2}$ & .48 & $\mathrm{PT} \times \mathrm{PT}^{2}$ & .23 \\
\hline $\mathrm{GD} \times \mathrm{GD}^{2} \times \mathrm{PT}$ & .55 & $A D \times A D^{2} \times P T$ & .40 \\
\hline $\mathrm{GD} \times \mathrm{GD}^{2} \times \mathrm{PT}^{2}$ & .53 & $A D \times A D^{2} \times P T^{2}$ & .38 \\
\hline $\mathrm{GD} \times \mathrm{PT} \times \mathrm{PT}^{2}$ & .50 & $\mathrm{AD} \times \mathrm{PT} \times \mathrm{PT}^{2}$ & .36 \\
\hline $\mathrm{GD}^{2} \times \mathrm{PT} \times \mathrm{PT}^{2}$ & .56 & $\mathrm{AD}^{2} \times \mathrm{PT} \times \mathrm{PT}^{2}$ & .31 \\
\hline $\mathrm{GD} \times \mathrm{GD}^{2} \times \mathrm{PT} \times \mathrm{PT}^{2}$ & .56 & $A D \times A D^{2} \times P T \times P T^{2}$ & .41 \\
\hline
\end{tabular}


at three attacks per $930 \mathrm{~cm}^{2}$ in all three phloem thicknesses (fig. 2). For example in phloem $1.5 \mathrm{~mm}$ thick, BP was 19 for three attacks and only 24 for seven attacks; for phloem $3.5 \mathrm{~mm}$ thick, BP was 63 for three attacks and 71 for seven attacks. When estimating brood production in wild populations, GD would be preferable to AD because average GD declines with increased AD. In addition, weather can greatly influence gallery length per attack.

The somewhat stronger association of brood production to GD than PT in ponderosa suggests MPB dynamics may be different than in lodgepole, where brood production is strongly associated with PT (Amman 1972a; Amman and Pace 1976). Average BP per $930 \mathrm{~cm}^{2}$ in phloem $3.5 \mathrm{~mm}$ thick is 75 beetles in ponderosa pine in contrast to 112 in lodgepole. Differences in continuity and intensity of infestations, which are generally more severe in lodgepole, may be related to these differences in brood production.

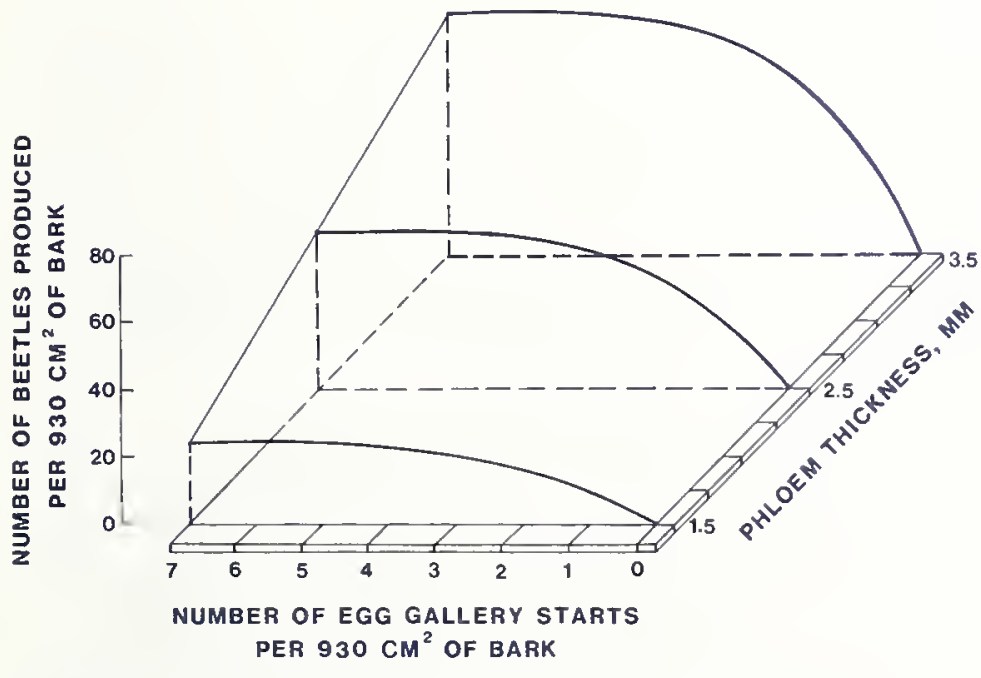

Figure 2-Mountain pine beetle brood production per unit area of ponderosa pine bark increases with both attack density and phloem thickness.

$$
\begin{aligned}
& \text { BP/930 } \mathrm{cm}^{2}=0.9256\left[\mathrm{UI}-\frac{\mathrm{UI}}{7^{\mathrm{n}}}(7-A D)^{\mathrm{n}}\right] \\
& \begin{aligned}
\mathrm{UI} & =(1045.2083)(0.03937 \text { PT })^{1.3} \\
& =\text { upper intercept } \\
\mathrm{n} & =2.78+(18.3944)(0.03937 \text { PT })^{1.3}
\end{aligned}
\end{aligned}
$$

where

PT $=$ phloem thickness in millimeters

$A D=$ attack density per $930 \mathrm{~cm}^{2}$

$P<0.01$

$R^{2}=0.38$

Limits: $0<A D<7$

\section{Beetle Size}

A multiple regression screen showed that female length (FL) was related to the linear effects of PT and GD. In this case, PT accounted for 22 percent $(\mathrm{P}<0.01)$ of the variance, and GD accounted for 11 percent
$(\mathrm{P}<0.05)$ of the variance in $\mathrm{FL}$ (table 3$)$. The combined model explained 35 percent $(P<0.001)$ of the variance in FL. The scaled effects are shown in figure 3.

Table 3-Multiple regression screen for length of mountain pine beetle females as a function

\begin{tabular}{|c|c|}
\hline Variables & $R^{2}$ \\
\hline GD & 0.11 \\
\hline $\mathrm{GD}^{2}$ & .09 \\
\hline PT & .22 \\
\hline $\mathrm{PT}^{2}$ & .24 \\
\hline $\mathrm{GD} \times \mathrm{GD}^{2}$ & .12 \\
\hline $\mathrm{GD} \times \mathrm{PT}$ & .35 \\
\hline $\mathrm{GD} \times \mathrm{PT}^{2}$ & .36 \\
\hline $\mathrm{GD}^{2} \times \mathrm{PT}$ & .33 \\
\hline $\mathrm{GD}^{2} \times \mathrm{PT}^{2}$ & .33 \\
\hline $\mathrm{PT} \times \mathrm{PT}^{2}$ & .24 \\
\hline $\mathrm{GD} \times \mathrm{GD}^{2} \times \mathrm{PT}$ & .35 \\
\hline $\mathrm{GD} \times \mathrm{GD}^{2} \times \mathrm{PT}^{2}$ & .36 \\
\hline $\mathrm{GD} \times \mathrm{PT} \times \mathrm{PT}^{2}$ & .36 \\
\hline $\mathrm{GD}^{2} \times \mathrm{PT} \times \mathrm{PT}^{2}$ & .35 \\
\hline $\mathrm{GD} \times \mathrm{GD}^{2} \times \mathrm{PT} \times \mathrm{PT}^{2}$ & .36 \\
\hline
\end{tabular}
of ponderosa pine phloem thickness (PT) and egg gallery density (GD)

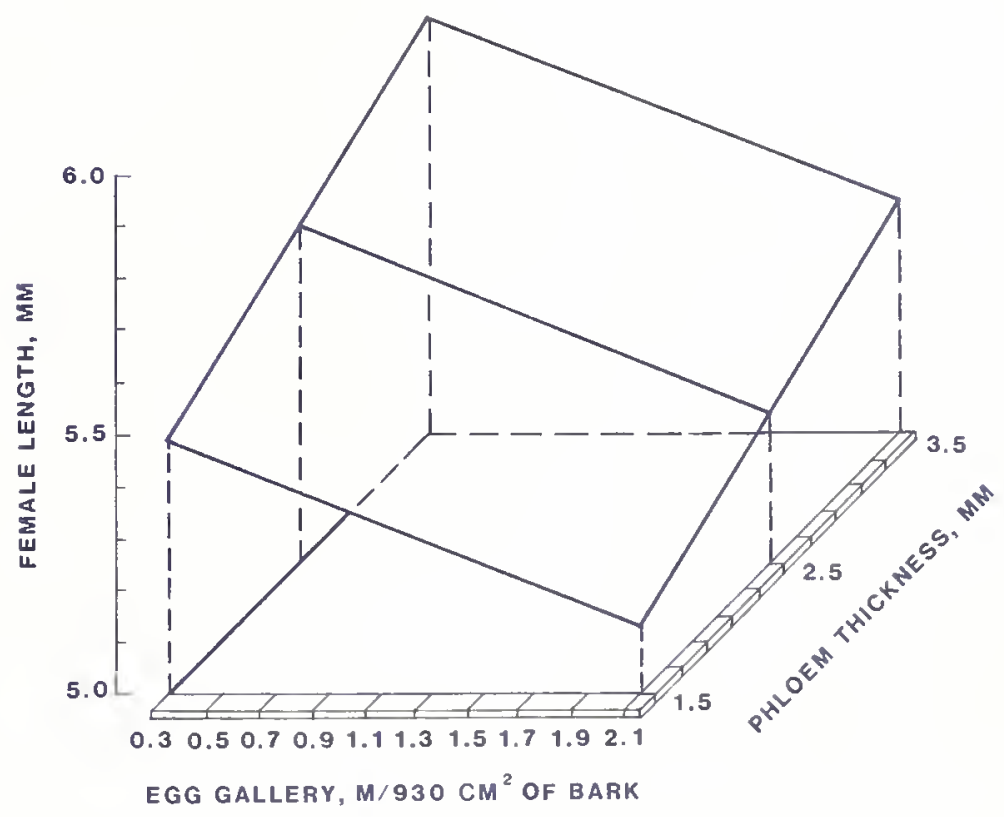

Figure 3-Female mountain pine beetle length declines as egg gallery density increases, but beetle length increases as phloem thickness increases.

$\mathrm{FL}=5.307-0.197 \mathrm{GD}+0.159 \mathrm{PT}$

where

$\mathrm{FL}=$ female length in millimeters

$\mathrm{GD}=$ gallery density in meters per $930 \mathrm{~cm}^{2}$

$\mathrm{PT}=$ phloem thickness in millimeters

$P<0.01$

$R^{2}=0.35$

Limits: $0.3<\mathrm{GD}<2.1$. 
Although sizes of both females and males showed the same trend, only female size was analyzed. Average female length at $0.3 \mathrm{~m}$ of egg gallery per $930 \mathrm{~cm}^{2}$ ranged from $5.49 \mathrm{~mm}$ for thin phloem to $5.81 \mathrm{~mm}$ for thick phloem (fig. 3). At $2.1 \mathrm{~m}$ of gallery per $930 \mathrm{~cm}^{2}$, female length ranged from $5.14 \mathrm{~mm}$ in thin phloem to $5.46 \mathrm{~mm}$ in thick phloem. Similar relations were observed in lodgepole pine (Amman and Pace 1976). However, beetle size is greater in ponderosa than in lodgepole for any specified combination of phloem thickness and egg gallery density, which suggests that ponderosa phloem is qualitatively better food than lodgepole phloem for mountain pine beetles. Even when MPB of a single population from lodgepole pine were reared in ponderosa and lodgepole pines, those from ponderosa were significantly larger than those from lodgepole (Amman 1982). Two effects associated with small MPB are oviposition of fewer eggs and smaller eggs than occurs with large beetles (Amman 1972b; McGhehey 1971; Reid 1962).

\section{Sex Ratio}

The percentages of new adult beetles that were female were not significantly correlated $(\mathrm{P}>0.05)$ with attack density in any of the three phloem thicknesses. Therefore, comparisons were made between percentages of beetles that were female from all attack densities. The percentage of new adult beetles that were female did not differ significantly ( $\mathrm{P}>0.05$ ) between thick $(66.8$ percent) and medium (67.0 percent) phloem, but was significantly less $(\mathrm{P}<0.005)$ in thin phloem $(62.9$ percent). Factors that adversely affect developing MPB generally result in lower survival of males than females. For exam. ple: drying (Amman and Rasmussen 1974; Cole and others 1976), cold storage (Safranyik 1976; Watson 1971), and thin phloem (Amman and Pace 1976) in lodgepole pine. The reduced percentage of females coming from thin rather than thick ponderosa pine phloem is just the opposite from the trend observed in lodgepole pine, where thin phloem yielded 72 percent female and thick phloem 66 percent female (Amman and Pace 1976). No explanation is offered for this apparent reversal. Additional observations are planned to determine if this difference in sex ratio between beetles from thick and thin ponderosa phloem is consistent.

\section{Emergence Time}

Emergence time of new adults was unrelated to attack density except in thick phloem, where a significant negative correlation occurred $(\mathrm{P}<0.05)$. Therefore, emergence times for all beetles, regardless of attack density, were combined for each phloem thickness. These data showed that emergence of beetles from thin phloem was delayed from that of beetles in medium and thick phloem. The time interval for 50 percent of the beetles, starting from introduction of parent adults into the bark areas, was approximately 82 days in thin phloem compared to 71 days in medium, and 75 in thick phloem. The delay in thin phloem is even more apparent later in the emergence cycle (fig. 4).

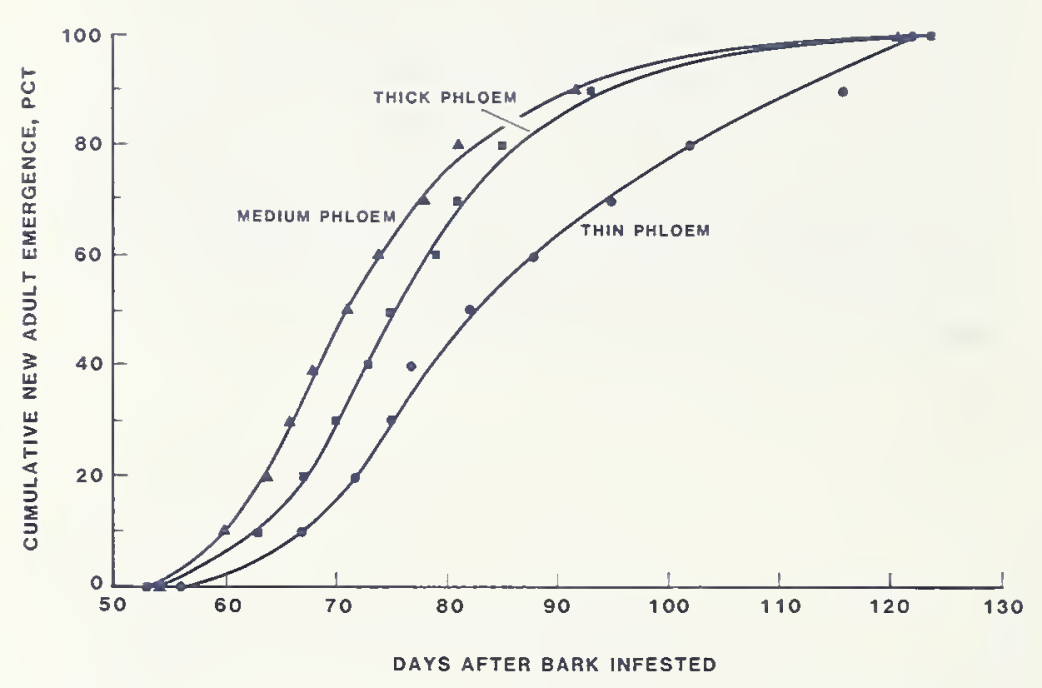

Figure 4-Cumulative percentage of mountain pine beetle emergence from three thicknesses of ponderosa pine phloem (hand-fitted curves).

The differences in time of emergence may be due to nutrition, with medium to thick phloem being best for beetle development. Larvae feeding in thin phloem, particularly those in later instars, probably are chewing outer bark and sapwood in addition to phloem as they feed, thus delaying development. These tissues probably are not as nutritious as phloem, which is readily available to larvae feeding in medium to thick phloem. The rate of beetle emergence was also slower in thin than in thick lodgepole pine phloem (Amman and Cole 1983).

\section{CONCLUSION}

The significant association of MPB brood production, beetle size, sex ratio, and time of emergence to phloem thickness in ponderosa pine indicates phloem thickness is an important factor in MPB dynamics in ponderosa pine forests. 


\section{REFERENCES}

Amman, Gene D. Mountain pine beetle emergence in relation to depth of lodgepole pine bark. Research Note INT-96. Ogden, UT: U.S. Department of Agriculture, Forest Service, Intermountain Forest and Range Experiment Station; 1969. 8 p.

Amman, Gene D. Mountain pine beetle brood production in relation to thickness of lodgepole pine phloem. Journal of Economic Entomology. 65: 138-140; 1972a.

Amman, Gene D. Some factors affecting oviposition behavior of the mountain pine beetle. Environmental Entomology. 1: 691-695; 1972b.

Amman, Gene D. Characteristics of mountain pine beetles reared in four pine hosts. Environmental Entomology. 11: 590-593; 1982.

Amman, Gene D.; Cole, Walter E. Mountain pine beetle dynamics in lodgepole pine forests. Part II: population dynamics. General Technical Report INT-145. Ogden, UT: U.S. Department of Agriculture, Forest Service, Intermountain Forest and Range Experiment Station; 1983. $59 \mathrm{p}$.

Amman, Gene D.; Pace, Vincent E. Optimum egg gallery densities for the mountain pine beetle in relation to lodgepole pine phloem thickness. Research Note INT-209. Ogden, UT: U.S. Department of Agriculture, Forest Service, Intermountain Forest and Range Experiment Station; 1976. 8 p.

Amman, Gene D.; Rasmussen, Lynn A. A comparison of radiographic and bark-removal methods for sampling of mountain pine beetle populations. Research Paper INT-151. Ogden, UT: U.S. Departinent of Agriculture, Forest Service, Intermountain Forest and Range Experiment Station; 1974. 11 p.

Blackman, M. W. The Black Hills beetle. Technical Publication 36. Syracuse, NY: Syracuse University, New York State College of Forestry; 1931. 77 p.

Cole, Dennis M. Estimation of phloem thickness in lodgepole pine. Research Paper INT-148. Ogden, UT: U.S. Department of Agriculture, Forest Service, Intermountain Forest and Range Experiment Station; 1973. $10 \mathrm{p}$.

Cole, Walter E.; Amman, Gene D.; Jensen, Chester E. Mathematical models for the mountain pine beetlelodgepole pine interaction. Environmental Entomology. 5: 11-19; 1976.

Craighead, F. C.; Miller, J. M.; Evenden, J. C.; Keen, F. P. Control work against bark beetles in western forests and an appraisal of its results. Journal of Forestry. 29: 1001-1018; 1931.

Haack, Robert A.; Wilkinson, Robert C.; Foltz, John L.; Corneil, Jeffrey A. Gallery construction and oviposition by Ips calligraphus (Coleoptera: Scolytidae) in relation to slash pine phloem thickness and temperature. Canadian Entomologist. 116: 625-632; 1984.

Hopkins, A. D. Practical information on the scolytid beetles of North American forests. I. Bark beetles of the genus Dendroctonus. Bulletin 83, part I. Washington, DC: U.S. Department of Agriculture, Bureau of Entomology; 1909. 169 p.
Jensen, Chester E. Matchacurve-3: multiple-component and multidimensional mathematical models for natural resource studies. Research Paper INT-146. Ogden, UT: U.S. Department of Agriculture, Forest Service, Intermountain Forest and Range Experiment Station; 1973. $42 \mathrm{p}$.

Jensen, Chester E.; Homeyer, J. W. Matchacurve-1 for algebraic transforms to describe sigmoid- or bell-shaped curves. Ogden, UT: U.S. Department of Agriculture, Forest Service, Intermountain Forest and Range Experiment Station; 1970. 22 p.

Jensen, Chester E.; Homeyer, J. W. Matchacurve-2 for algebraic transforms to describe curves of the class $\mathrm{X}^{\mathrm{n}}$. Research Paper INT-106. Ogden, UT: U.S. Department of Agriculture, Forest Service, Intermountain Forest and Range Experiment Station; 1971. 39 p.

Klein, William H.; Bennett, Dayle D.; Young, Robert W. A pilot survey to measure annual mortality of lodgepole pine caused by the mountain pine beetle. Report 78-4. Ogden, UT: U.S. Department of Agriculture, Forest Service, Intermountain Region and Methods Applications Group; 1979. 15 p.

Lyon, R. L. A useful secondary sex character in Dendroctonus bark beetles. Canadian Entomologist. 90: $582-584 ; 1958$.

McGhehey, J. H. Female size and egg production of the mountain pine beetle, Dendroctonus ponderosae Hopkins. Information Report NOR-X-9. Edmonton, AB: Canadian Forestry Service, Northern Forest Research Centre; 1971. 18 p.

McGregor, Mark D. Mountain pine beetle: The conflict between people and the beetle. In: Loomis, Robert C.; Tucker, Susan; Hofacker, Thomas H., eds. Insect and disease conditions in the United States 1979-83. General Technical Report WO-46. Washington, DC: U.S. Department of Agriculture, Forest Service; 1985: 16-23.

McGregor, M. D.; Hamel, D. R.; Kohler, S. Status of mountain pine beetle infestations, Glacier National Park and Glacier View Ranger District, Flathead National Forest, Montana, 1977. Report 78-6. Missoula, MT: U.S. Department of Agriculture, Forest Service, Northern Region; 1978. 14 p.

Reid, R. W. Biology of the mountain pine beetle, Dendroctonus monticolae Hopkins, in the east Kootenay region of British Columbia. II. Behaviour in the host, fecundity, and internal changes in the female. Canadian Entomologist. 94: 605-613; 1962.

Safranyik, L. Size- and sex-related emergence, and survival in cold storage, of mountain pine beetle adults. Canadian Entomologist. 108: 209-212; 1976.

Snedecor, George W. Statistical methods. Ames, IA: Iowa State College Press; 1956. 534 p.

Watson, J. A. Survival and fecundity of Dendroctonus ponderosae (Coleoptera: Scolytidae) after laboratory storage. Canadian Entomologist. 103: 1381-1385; 1971. 

Amman, Gene D.; Pasek, Judith E. Mountain pine beetle in ponderosa pine: effects of phloem thickness and egg gallery density. Research Paper INT-367. Ogden, UT: U.S. Department of Agriculture, Forest Service, Intermountain Research Station; $19867 \mathrm{p}$.

Effects of phloem thickness in ponderosa pine (Pinus ponderosa) on mountain pine beetle (Dendroctonus ponderosae) were determined in a laboratory study. Brood production, beetle size, sex ratio, and rate of emergence were significantly related to phloem thickness, egg gallery density, and attack density.

KEYWORDS: Scolytidae, bark beetles, Dendroctonus ponderosae, phloem, Pinus ponderosa 


\section{INTERMOUNTAIN RESEARCH STATION}

The Intermountain Research Station provides scientific knowledge and technology to improve management, protection, and use of the forests and rangelands of the Intermountain West. Research is designed to meet the needs of National Forest managers,

Federal and State agencies, industry, academic institutions, public and private organizations, and individuals. Results of research are made available through publications, symposia, workshops, training sessions, and personal contacts.

The Intermountain Research Station territory includes Montana, Idaho, Utah, Nevada, and western Wyoming. Eighty-five percent of the lands in the Station area, about 231 million acres, are classified as forest or rangeland. They include grasslands, deserts, shrublands, alpine areas, and forests. They provide fiber for forest industries, minerals and fossil fuels for energy and industrial development, water for domestic and industrial consumption, forage for livestock and wildlife, and recreation opportunities for millions of visitors.

Several Station units conduct research in additional western States, or have missions that are national or international in scope.

Station laboratories are located in:

Boise, Idaho

Bozeman, Montana (in cooperation with Montana State University)

Logan, Utah (in cooperation with Utah State University)

Missoula, Montana (in cooperation with the University of Montana)

Moscow, Idaho (in cooperation with the University of Idaho)

Ogden, Utah

Provo, Utah (in cooperation with Brigham Young University)

Reno, Nevada (in cooperation with the University of Nevada)

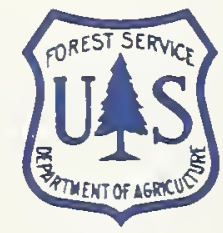

